University of Nebraska - Lincoln

DigitalCommons@University of Nebraska - Lincoln

\title{
Premature Expression of the Latency-Related RNA Encoded by Bovine Herpesvirus Type 1 Correlates With Higher Levels of Beta Interferon RNA Expression in Productively Infected Cells
}

\author{
Sandra Perez \\ University of Nebraska - Lincoln \\ Florencia Meyer \\ University of Nebraska-Lincoln, florencia.meyer@msstate.edu \\ Kazima Saira \\ University of Nebraska - Lincoln \\ Alan R. Doster \\ University of Nebraska - Lincoln, adoster1@unl.edu \\ Clinton J. Jones \\ University of Nebraska - Lincoln, cjones2@unl.edu
}

Follow this and additional works at: https://digitalcommons.unl.edu/vetscipapers

Part of the Veterinary Medicine Commons

Perez, Sandra; Meyer, Florencia; Saira, Kazima; Doster, Alan R.; and Jones, Clinton J., "Premature Expression of the Latency-Related RNA Encoded by Bovine Herpesvirus Type 1 Correlates With Higher Levels of Beta Interferon RNA Expression in Productively Infected Cells" (2008). Papers in Veterinary and Biomedical Science. 109.

https://digitalcommons.unl.edu/vetscipapers/109

This Article is brought to you for free and open access by the Veterinary and Biomedical Sciences, Department of at DigitalCommons@University of Nebraska - Lincoln. It has been accepted for inclusion in Papers in Veterinary and Biomedical Science by an authorized administrator of DigitalCommons@University of Nebraska - Lincoln. 


\title{
Premature expression of the latency-related RNA encoded by bovine herpesvirus type 1 correlates with higher levels of beta interferon RNA expression in productively infected cells
}

\author{
Sandra Perez, ${ }^{1,4}$ Florencia Meyer, ${ }^{2,3}$ Kazima Saira, ${ }^{1,2}$ Alan Doster, ${ }^{1,2}$ and Clinton Jones ${ }^{1,2}$ \\ ${ }^{1}$ Department of Veterinary and Biomedical Sciences, University of Nebraska-Lincoln, Fair Street at East Campus Loop, Lincoln, NE \\ 68583-0905, USA \\ 2 Nebraska Center for Virology, University of Nebraska-Lincoln, Fair Street at East Campus Loop, Lincoln, NE 68583-0905, USA \\ ${ }^{3}$ School of Biological Sciences, University of Nebraska-Lincoln, Lincoln, NE 68588, USA \\ ${ }^{4}$ Present address: Centers for Disease Control, 1600 Clifton Rd, Atlanta, GA 30333, USA. \\ Corresponding author - Clinton Jones, cjones@unlnotes.unl.edu
}

\begin{abstract}
Bovine herpesvirus type 1 (BHV-1) is an important pathogen that can initiate bovine respiratory disease complex. Like other members of the subfamily Alphaherpesvirinae, BHV-1 establishes latency in sensory neurons. The latency-related (LR) gene expresses a family of alternatively spliced transcripts in infected sensory neurons that have the potential to encode several LR proteins. An LR mutant virus that contains three stop codons near the 5' terminus of the first open reading frame in the LR gene does not express two LR proteins or reactivate from latency. In addition, the LR mutant virus induces higher levels of apoptosis in trigeminal ganglionic neurons and grows less efficiently in certain tissues of infected calves. In spite of the reduced pathogenesis, the LR mutant virus, wild-type BHV-1, and the LR rescued virus exhibit identical growth properties in cultured bovine cells. In this study, we demonstrated that during early phases of productive infection the LR mutant virus expressed higher levels of LR-RNA relative to the LR rescued virus or wt BHV-1. Bovine kidney cells infected with the LR mutant virus also induced higher levels of beta interferon RNA and interferon response genes. These results suggest that inappropriate expression of LR-RNA, in the absence of LR protein expression, may influence the latency-reactivation cycle and pathogenic potential of BHV-1.
\end{abstract}

A supplemental table showing primers used to detect IFN response and viral gene expression is attached to the end of this paper.

\section{Introduction}

Infection of cattle with bovine herpesvirus type 1 (BHV1) can lead to conjunctivitis, pneumonia, genital disorders, abortions or bovine respiratory disease complex, a serious upper respiratory tract infection (Tikoo et al., 1995). Infection of calves or cultured bovine cells leads to rapid cell death and an increase in apoptosis (Devireddy \& Jones, 1999; Winkler et al., 1999). As with other members of the subfamily Alphaherpesvirinae, viral gene expression is temporally regulated in three distinct phases: immediate-early (IE), early (E) or late (L) (Jones, 2003).

Infection of cultured human cells with herpes simplex virus type 1 (HSV-1) leads to the production and secretion of interferon (IFN). ICP0, ICP34.5 and Us11 are HSV-1 genes that inhibit IFN activation post-infection (p.i.) (Lin et al., 2004; Mossman et al., 2000, 2001; Mossman \& Smiley, 2002; Peters, et al., 2002). The viral glyco- protein $\mathrm{gD}$ activates interferon response factor 3 (IRF3) and consequently IFN- $\alpha$ production in mononuclear cells (Katze et al., 2002). Mice lacking type I and type II IFN receptors in combination with RAG-2 gene deletions die within a few days following BHV-1 infection (Abril et al., 2004). In contrast, BHV-1 infection of wildtype (wt) mice does not lead to clinical symptoms, confirming that IFN signalling pathways repress productive infection. To date, bICP0 is the only BHV-1 encoded protein known to inhibit IFN responses (Henderson et al., 2005; Saira et al., 2007).

The latency-related (LR) gene is abundantly transcribed in trigeminal ganglia (TG) of latently infected calves (Kutish et al., 1990; Rock et al., 1987, 1992) and is antisense with respect to the bICP0 gene (Jones, 1998, 2003; Jones et al., 2006). The LR gene has two open reading frames (ORF-1 and ORF-2), and two reading frames that lack an initiating ATG (RF-B and RF-C) (Figure 1a). 


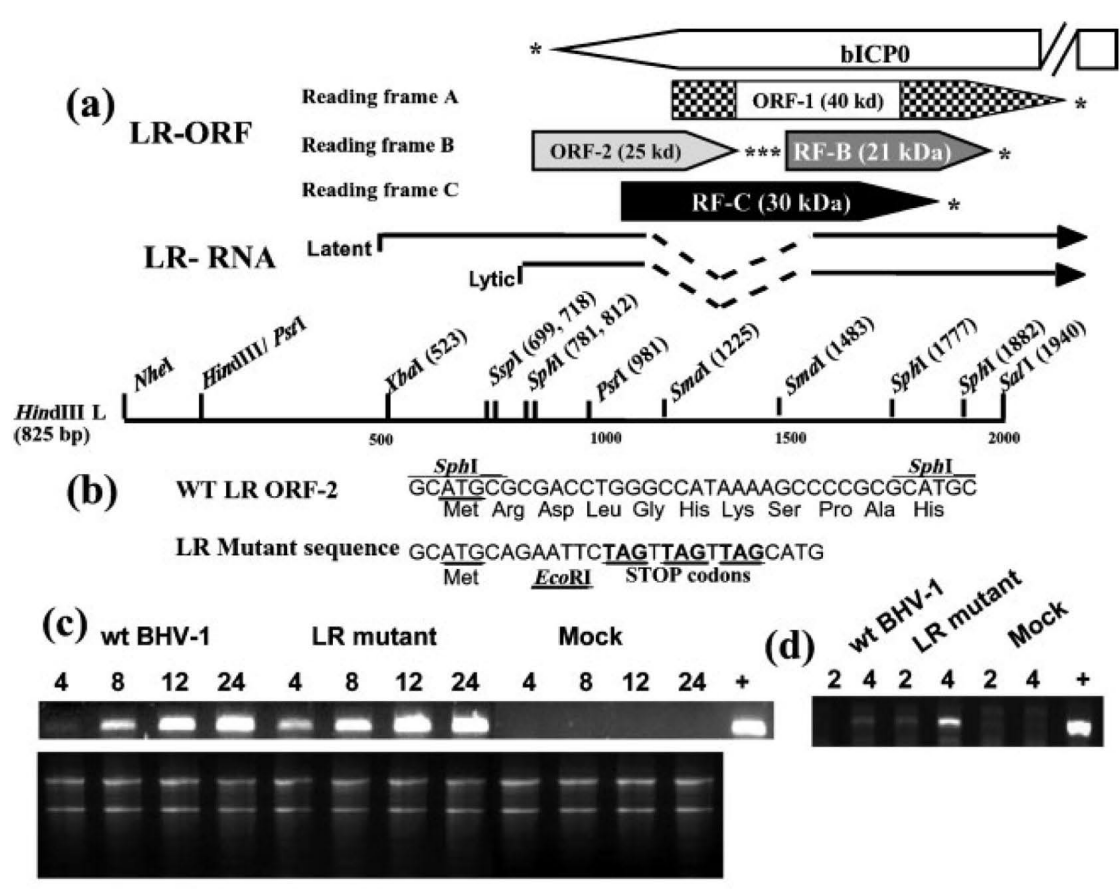

(e)

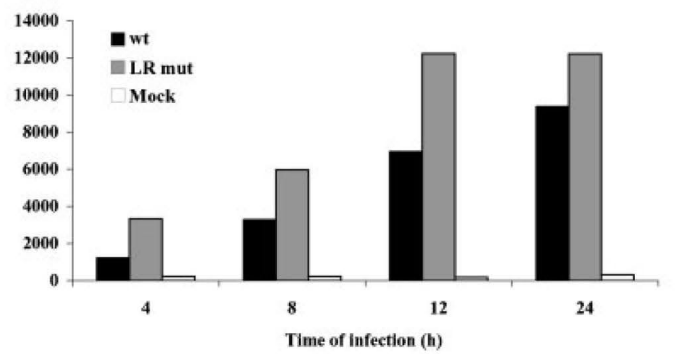

(f)

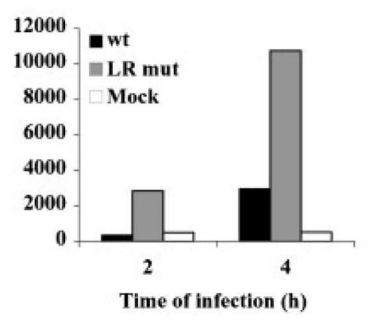

Figure 1. Schematic of the BHV-1 LR gene and primers used in this study. (a) Partial restriction map, location of LR-RNA, organization of LR ORFs and the bICPO ORF. The start sites for LR transcription during latency and productive infection were described previously (Hossain et al., 1995). Reading frames (RF) B and $\mathrm{C}$ contain an open reading frame, but lack an initiating Met. The $\left({ }^{*}\right)$ denotes position of stop codons that are in-frame with the respective ORF. (b) DNA sequence of the Sphl fragment and mutant oligonucleotide. The first ATG in the wt sequence is the first in-frame ATG for ORF2 and it is underlined. Stop codons in the mutant oligonucleotide are in all three reading frames (bold and underlined). The EcoRI restriction enzyme site (GAATTC) was incorporated into the mutant oligonucleotide to facilitate screening. (c) MDBK cells were infected with the designated virus strains using an m.o.i. of 5 and total RNA prepared as described in Methods. Semi-quantitative RT-PCR analysis of LR-RNA expression in productively infected MDBK cells. To specifically prime LR-cDNA synthesis, primer 1980 was used. Primer L3D+ and primer L3D- were used to amplify LR-cDNA. The LR primers are described in Supplementary Table S1. Synthesis of cDNA was conducted with $3 \mu$ g total RNA and $1.25 \mu \mathrm{M}$ primer 1980. PCR amplification was carried out in the presence of $20 \%$ DMSO for 35 cycles by denaturing at $95{ }^{\circ} \mathrm{C}$ for $50 \mathrm{~s}$, annealing at $55^{\circ} \mathrm{C}$ for $45 \mathrm{~s}$ and extending at $72{ }^{\circ} \mathrm{C}$ for $50 \mathrm{~s}$. At the end of the PCR, $10 \mathrm{~min}$ at $72{ }^{\circ} \mathrm{C}$ ensured the complete extension of amplified products. Samples were melted at $95^{\circ} \mathrm{C}$ for $6 \mathrm{~min}$ prior to cycling. The lower panel is an ethidium bromide stained gel that shows rRNA. (d) Levels of LR-RNA during the early phase of productive infection. The experiment was conducted as described for (c). (e and f) Quantification of results shown in (c) and (d).
A mutant BHV-1 virus (LR mutant virus) that contains three stop codons at the beginning of ORF-2 and also lacks $25 \mathrm{bp}$ of wt sequence at the beginning of ORF2 was constructed (Figure 1b) (Inman et al., 2001). The LR mutant virus grows to similar titres to the wt BHV-1 or LR rescued virus in cultured bovine cells, indicating that expression of LR proteins is not necessary for productive infection. When bovine cells are infected with the LR mutant virus, proteins containing all or part of ORF2 or RF-C are not expressed (Hossain et al., 1995; Jiang et al., 1998, 2004). Calves infected with the LR mutant virus exhibit diminished clinical symptoms and reduced shedding of infectious virus in the eye, tonsil or TG (Inman et al., 2001, 2002; Perez et al., 2005). The LR mutant virus does not reactivate from latency following dexa- methasone (DEX) treatment (Inman et al., 2002), indicating that LR protein expression is crucial for the latencyreactivation cycle. LR gene products inhibit mammalian cell growth by blocking $S$ phase entry (Geiser \& Jones, 2005; Schang et al., 1996), bICP0 expression (Bratanich et al., 1992; Geiser et al., 2002; Schang et al., 1996) and apoptosis (Ciacci-Zanella et al., 1999; Henderson et al., 2004). LR protein expression is necessary for inhibiting apoptosis, in part, because an LR protein binds to two proteins that induce apoptosis, Bid and Cdc42 (Meyer et al., 2007). In contrast, LR protein expression is not necessary for inhibiting cell growth or bICP0 expression. We predict that non-protein coding functions encoded by LRRNA cooperate with LR proteins to regulate the latencyreactivation cycle. 
In this study, we compared IFN RNA expression in bovine cells following infection with the LR mutant virus or virus strains that express wt LR gene products. The LR mutant virus expresses higher levels of IFN- $\beta$ RNA and LR-RNA during early stages of productive infection. In tonsils of calves acutely infected with the LR mutant virus, higher levels of IFN RNA were also expressed. Collectively, these studies suggest that inappropriate levels of LR-RNA prematurely stimulate IFN$\beta$ RNA expression and reduce the pathogenic potential of the LR mutant virus.

\section{Methods}

Viruses and cells. The Cooper strain of BHV-1 (wt virus) was obtained from the National Veterinary Services Laboratory, Animal and Plant Health Inspection Services, Ames, Iowa, USA. For construction of the LR mutant virus, $25 \mathrm{bp}$ of the LR gene sequence from the Cooper strain were replaced with an oligonucleotide that contains a unique EcoRI restriction site and three stop codons to prevent protein expression (Inman et al., 2001, 2002) (Figure 1a and b). The LR mutant rescued virus was rescued by substituting wt sequences back into the LR gene.

Madin-Darby bovine kidney cells (MDBK, ATCC CCL-22) were maintained in Earle's modified Eagle's medium supplemented with $5 \%$ fetal calf serum. To prepare virus stocks, MDBK cells were infected with wt BHV-1, the LR mutant virus or the LR mutant rescued virus at an m.o.i. of 0.01. For the experiments described in this study, an m.o.i. of 5 was used.

Animal studies. BHV-1-free cross-bred calves $(\sim 200 \mathrm{~kg})$ were used for this study. Calves were inoculated with $10^{7}$ p.f.u. of wt BHV-1, the LR rescued virus or the LR mutant virus into each nostril and conjunctiva for a total of $4 \times 10^{7}$ p.f.u. per animal as described previously (Inman et al., 2002; Lovato et al., 2003; Perez et al., 2005; Winkler et al., 1999, 2000). Calves were housed under strict isolation and given antibiotics before and after BHV-1 infection to prevent secondary bacterial infections. At 60 days post-infection (p.i.), wt BHV-1, the LR rescued virus and the LR mutant-infected calves were injected intravenously with $100 \mathrm{mg}$ DEX. Additional intramuscular injections $(25 \mathrm{mg})$ of DEX were given at 2 and 4 days after the initial intravenous injection to ensure that reactivation occurs. Total RNA prepared from TG and tonsils was from calf studies that were previously described (Inman et al., 2002; Lovato et al., 2003; Perez et al., 2005; Winkler et al., 1999, 2000).

RNA extraction. RNA was extracted from cultured cells or tissue (Chomczynski \& Sacchi, 1987). Tissue from tonsil or TG was first minced into small pieces, placed into $10 \mathrm{ml}$ solution D [4 M guanidine thiocyanate, $25 \mathrm{mM}$ sodium citrate ( $\mathrm{pH}$ 7.0), $0.5 \%$ sarkosyl and $14 \mathrm{mM}$ $\beta$-mercaptoethanol] and homogenized. Two phenol extractions were performed. RNA concentrations were determined spectrophotometrically $(260 \mathrm{~nm})$ and RNA was reprecipitated in 3 volumes of ethanol.

DNase treatment and reverse transcription (RT). Three micrograms of RNA was treated with 1 U RNase-free DNase I (Gibco-BRL) for $15 \mathrm{~min}$ at $20^{\circ} \mathrm{C}$ in the presence of an RNase inhibitor (RNAsin; Promega). After DNase I treatment, samples were incubated at $65^{\circ} \mathrm{C}$ for $7.5 \mathrm{~min}$ in the presence of $2 \mathrm{mM}$ EDTA to eliminate DNase I activity. RT reactions were performed with random hexamers or the LR-specific primer 1980 at $65{ }^{\circ} \mathrm{C}$ for $7.5 \mathrm{~min}$ and chilled on ice. Sixteen microlitres of ice-cold RT mix [20 mM Tris/ $\mathrm{HCl}$ (pH 8.3), $50 \mathrm{mM} \mathrm{KCl}, 2.5 \mathrm{mM} \mathrm{MgCl}_{2}, 100 \mu \mathrm{g}$ BSA ml-1, $1 \mathrm{mM}$ dithiothreitol, $0.5 \mathrm{mM}$ each deoxynucleotide triphosphate (dNTPs) and $10 \mathrm{U}$ RNAsin] was added. The reaction mixture was incubated for $10 \mathrm{~min}$ at $25^{\circ} \mathrm{C}$ and then for $50 \mathrm{~min}$ at $42{ }^{\circ} \mathrm{C}$. One microlitre of reverse transcriptase was added to each tube and placed at $42{ }^{\circ} \mathrm{C}$ in a water bath for $50 \mathrm{~min}$. As a control for DNA contamination in the RNA samples, $3 \mu \mathrm{g}$ RNA (DNase I treated) was mixed with ice-cold RT mix lacking reverse transcriptase.

PCR. An aliquot $(2 \mu \mathrm{l})$ of the RT reaction mixture was used for each PCR, using primers specific for bovine IFN- $\alpha$, IFN- $\beta$, IFN- $\gamma$, Mx1a and LR genes. Amplification of $\beta$-actin was used as an internal control. PCRs were carried out in a total of $50 \mu$ containing $1 \times$ commercial PCR buffer, $5 \mathrm{mM} \mathrm{MgCl}_{2}, 200 \mu \mathrm{M}$ each dNTP, $1 \mu \mathrm{M}$ each primer and Taq polymerase. Amplification was carried out for 32 cycles by denaturing at $95^{\circ} \mathrm{C}$ for $1 \mathrm{~min}$, annealing at $53^{\circ} \mathrm{C}$ (IFN- $\alpha 1$, IFN- $\gamma$ and Mx1a) or $55^{\circ} \mathrm{C}$ (IFN- $\beta 1$, IFN- $\beta 2$ and IFN- $\beta 3$ ) for 1 min and extending at $72{ }^{\circ} \mathrm{C}$ for $2 \mathrm{~min}$. Upon completion of the last cycle, the reaction mixtures were further incubated at $72{ }^{\circ} \mathrm{C}$ for $7 \mathrm{~min}$ to ensure complete extension of the amplified product. PCR products were electrophoresed on $2 \%$ agarose gels and stained with ethidium bromide. Primers used for these studies are shown in Supplementary Table S1 (appended).

\section{Results}

\section{LR mutant virus prematurely expresses higher levels of LR-RNA}

Although the LR mutant virus expressed abundant levels of LR-RNA during latency (Inman et al., 2002), this study did not compare LR-RNA levels expressed by the LR mutant virus to virus strains expressing wt LR products. To compare LR-RNA expression in productively infected MDBK, semi-quantitative RT-PCR was performed using strand-specific primers to synthesize LR-cDNA (primer 1980), and primers that specifically amplify LRcDNA (see Supplementary Table S1). This approach was used instead of Northern blotting because LR-RNA overlaps the bICP0 transcript (Figure 1a), and ORF-E coding sequences are near the $5^{\prime}$ terminus of LR-RNA (Inman et al., 2004). Surprisingly, LR-RNA was readily detected in cells infected with the LR mutant virus, but not with wt BHV-1, at $4 \mathrm{~h}$ p.i. (Figure $1 \mathrm{c}$ and e). Additional studies confirmed that the LR mutant virus consistently expressed higher levels of LR-RNA at $4 \mathrm{~h}$ p.i. (Figure 1d and f). Furthermore, there was a faint band detected when MDBK cells were infected for $2 \mathrm{~h}$ with the LR mutant virus, but not with wt BHV-1 (Figure 1d and f) or the rescued virus (data not shown). Slightly higher levels of the LR-transcript were also detected in MDBK cells at 12 or $24 \mathrm{~h}$ p.i. with the LR mutant virus versus wt BHV-1 or the LR rescued virus (Figure $1 \mathrm{c}$ and e). As expected, rRNA levels were similar for all samples after measuring total RNA levels by $\mathrm{OD}_{260}$ and loading equal amounts on an agarose gel (Figure 1c, bottom panel). In summary, this study suggested that the LR mutant virus prematurely expressed higher levels of LR-RNA.

\section{The LR mutant virus induces higher levels of IFN- $\beta$ and IFN-responsive genes during productive infection}

The finding that LR-RNA expression occurred earlier in MDBK cells infected with the LR mutant virus suggested 
that a stronger IFN response may occur because LRRNA has the potential to base pair with bICP0 mRNA and also LR-RNA contains regions that have the potential to form double-stranded structures. To test whether this prediction was true, we compared IFN RNA expression in productively infected MDBK cells following infection with the LR mutant virus or a virus that expresses wt LR gene products. An initial study was performed to prove that MDBK cells were responsive to stimuli that induce IFN production. To this end, MDBK cells were infected with wt BHV-1 or treated with $10 \mu \mathrm{g}$ imiquimod (Invitrogen) $\mathrm{ml}^{-1}$, a compound that stimulates IFN and cytokine production (Megyeri et al., 1995). Following treatment with imiquimod, IFN- $\beta$ promoter activity increased as a function of time for $24 \mathrm{~h}$ and was approximately seven times higher compared with untreated cells (Figure 2). At 24 or $30 \mathrm{~h}$ p.i., IFN- $\beta$ promoter activity was stimulated five- to sixfold higher than mock-infected cells. Thus, MDBK cells were responsive to factors that induce an IFN response.

To examine IFN RNA expression in cells infected with BHV-1, RT-PCR was performed using primers directed against specific IFN subtypes (see Supplementary Table S1). RT-PCR was used for these studies because antibodies that recognize bovine IFN- $\beta$ subtypes are not commercially available and it is difficult to generate probes for Northern blots that recognize a single IFN- $\beta$ subtype. In contrast to humans or mice, cattle contain three different IFN- $\beta$ genes that are differentially regulated because they have distinct promoters (Valarcher et al., 2003; Wilson et al., 1983). When MDBK cells were infected with the LR mutant virus, IFN- $\beta 1$ was readily detected at $4 \mathrm{~h}$ p.i., whereas it was not detected until $8 \mathrm{~h}$ p.i. with the wt virus (Figure $3 a$ ) or the LR rescued virus (data not shown). IFN- $\beta 1$ RNA was detected in cultures infected with the wt virus at 8, 12 and $24 \mathrm{~h}$ p.i., but RNA levels were twoto fourfold lower compared with that detected in cells infected with the LR mutant virus (Figure $3 b$ ). IFN- $\beta 3$ transcripts were readily detected at $4,8,12$ and $24 \mathrm{~h}$ p.i. with the LR mutant virus, but not until $24 \mathrm{~h}$ p.i. with wt BHV1. IFN- $\beta 3$ RNA levels were approximately 10 -fold higher at 8 and $12 \mathrm{~h}$ p.i. (Figure $3 \mathrm{~b}$ ). Finally, IFN- $\beta 2$ expression was detected at $24 \mathrm{~h}$ following infection with wt BHV-1, whereas it was only detected at $12 \mathrm{~h}$ p.i. with the LR mutant virus (Figure $3 a$ and $b$ ).

Although IFN- $\alpha 1$ RNA was detected at the same time points in MDBK cells following infection with the LR mutant virus, wt BHV-1 (Figure 3a) or the LR rescued virus (data not shown), there was approximately twofold higher levels of IFN- $\alpha$ following infection with the LR mutant virus for 4,8 and $12 \mathrm{~h}$ p.i. (Figure $3 \mathrm{~b}$ ). The transcript encoded by the IFN-inducible gene, Mx1a, was detected following infection with the LR mutant virus at $4 \mathrm{~h}$ p.i., whereas this transcript was not detected until $12 \mathrm{~h}$ p.i. with wt BHV-1. In addition, there was two- to four- fold more Mx1a in cells infected with the LR mutant virus (Figure 3b). Expression of ISG54, another IFN-inducible gene, was also detected earlier in cells infected with the LR mutant virus (Figure 3a and b). Finally, expression of a third IFN-inducible gene, ISP15, was detected at 12 and $24 \mathrm{~h}$ p.i. in cells infected with the LR mutant virus, and there was at least twofold more ISP15 RNA compared with cells infected with the wt virus (Figure 3a and b). As expected, none of the IFN subtypes examined in this study was detected in MDBK cells prior to infection or in mock-infected cells (Figure 3a; 0 lane or the mock panels). In summary, this study indicated that MDBK cells infected with the LR mutant virus induced a stronger IFN response during early stages of productive infection.

\section{Analysis of IFN in calves infected with BHV-1}

In contrast to cultured cells, the LR mutant virus grows less efficiently than wt virus in bovine conjunctiva (Inman et al., 2001), TG (Inman et al., 2002) or pharyngeal

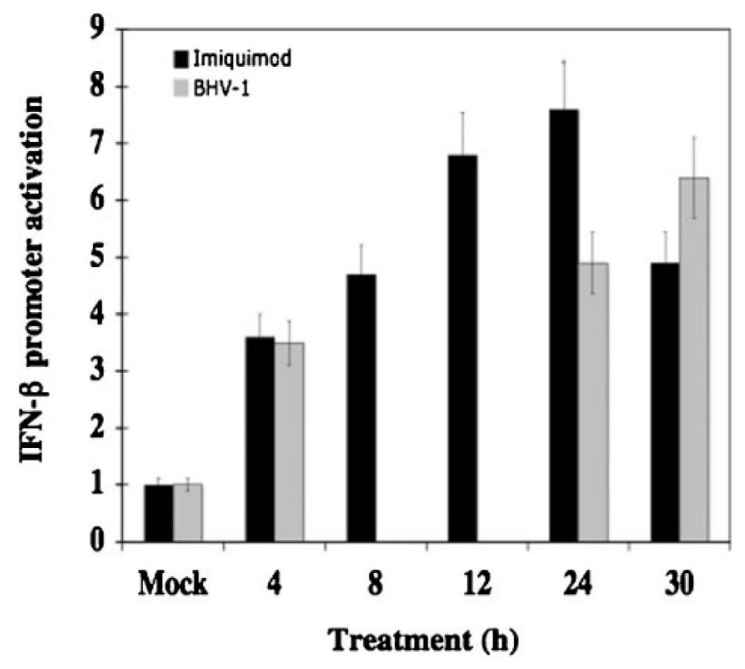

Figure 2. Activation of IFN- $\beta$ promoter activity by imiquimod and BHV-1. The IFN- $\beta$ chloramphenicol acetyltransferase (CAT) reporter plasmid $(2 \mu \mathrm{g})$ was transfected into MDBK cells using TransIT transfection reagents (Mirus) as described by the manufacturer. The IFN- $\beta$ CAT plasmid was obtained from Dr Stavros Lomvardas (Columbia University, NY, USA), and contains a minimal human IFN- $\beta$ promoter $(-110$ to +20$)$ upstream of the bacterial CAT gene. Cells were incubated with the transfection mix for $5 \mathrm{~h}$ and then replaced with fresh medium. Cells were treated with $10 \mu \mathrm{g}$ imiquimod (Invitrogen) $\mathrm{ml}^{-1}$ or infected with BHV-1 using an m.o.i. of 5 for the designated number of hours. All samples were treated such that cells were harvested at $40 \mathrm{~h}$ post-transfection. Cells were lysed by three freeze-thaw cycles in $250 \mathrm{mM}$ Tris/ $\mathrm{HCl}(\mathrm{pH} 8.0)$. CAT assays were performed with $0.2 \mu \mathrm{Ci}(7.4 \mathrm{kBq})$ $\left[{ }^{14} \mathrm{C}\right]$ chloramphenicol (Amersham Biosciences, Cat\# CFA754) and $0.5 \mathrm{mM}$ acetyl CoA (Sigma, Cat\# A2181) as previously described (Saira et al., 2007; Zhang \& Jones, 2005; Zhang et al., 2006). CAT activity is expressed as fold induction relative to the vector control. Transfection experiments for CAT assays were repeated at least three times. 

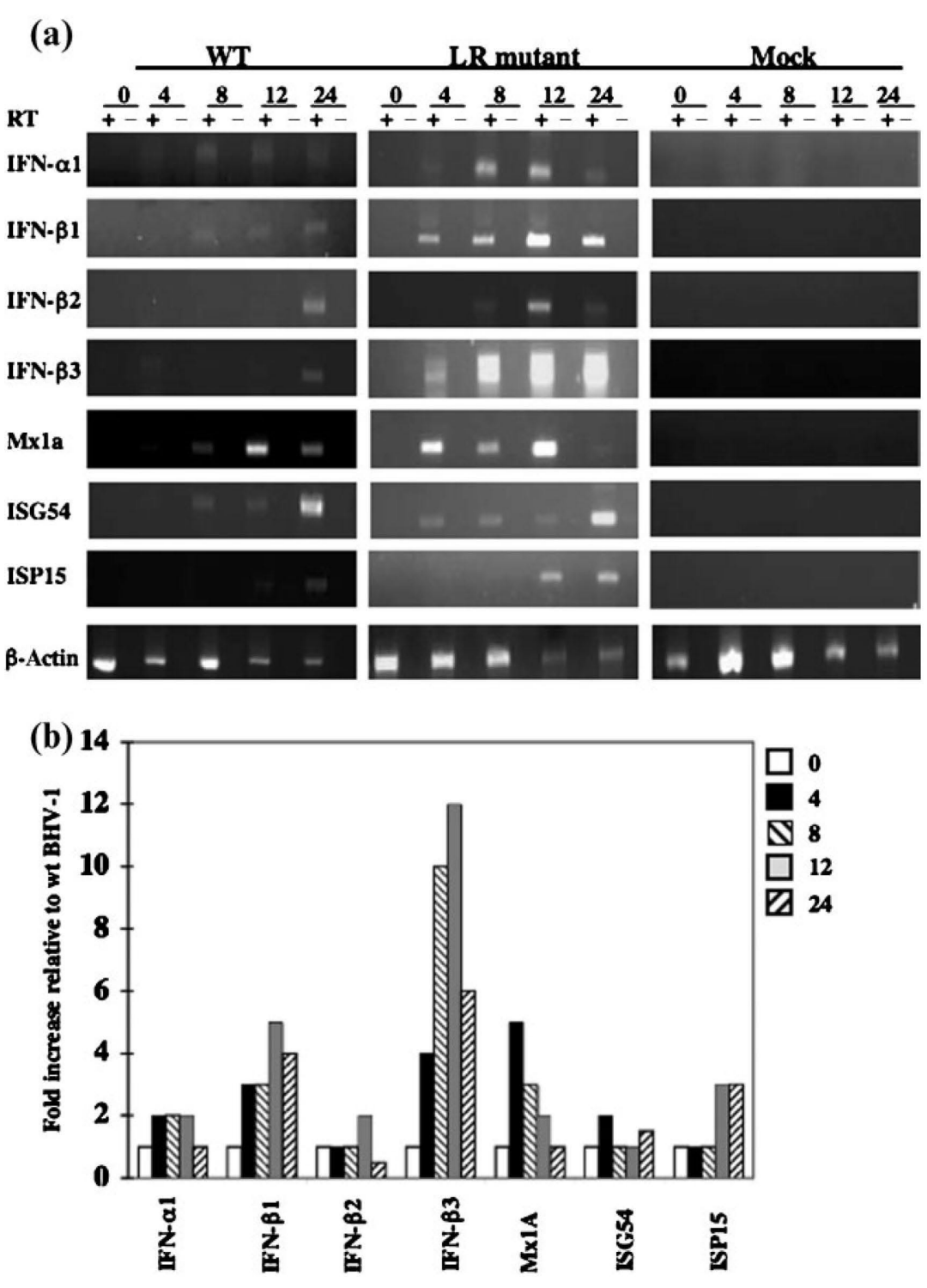

Figure 3. Induction of type I interferon response in MDBK cells infected with wt BHV-1 or the LR mutant strain. (a) MDBK cells were mock infected or infected with wt BHV-1 or the LR mutant virus at an m.o.i. of 5 for the designated time. Total RNA was extracted at the indicated hours p.i. cDNA synthesis was performed with random hexamers as previously described (Perez et al., 2005). For $\beta$-actin, results of RT reactions with $(+)$ or without $(-)$ reverse transcriptase are shown. The primers used for the $\mathrm{PCR}$ reactions are described in the Supplementary Table S1. The respective PCR products migrated as predicted. (b) The intensity of bands from Figure 3(a) was analysed using a Bio-Rad image analyser. The values for the LR mutant virus were divided by the values obtained for the wt virus infection. For those values in which there was not a detectable band, a value of 1 was assigned. The fold difference is shown on the $y$-axis. The results reflect the difference for just the study in (b), but the trend was nearly the same for two other replicates. tonsil (Perez et al., 2005), suggesting that in certain tissues of infected calves an enhanced IFN response may reduce shedding of the LR mutant virus. To test this possibility, total RNA was prepared from tonsils or TG of acutely infected calves ( 4 or 6 days p.i.) and the presence of IFN subtypes was detected by RT-PCR. The respective RNA preparations were subjected to cDNA synthesis using random primers and the designated primers described in Supplementary Table S1 were used to amplify cDNA. In general, IFN- $\alpha 1$, the three IFN- $\beta$ subtypes and IFN- $\gamma$ RNA were consistently detected in tonsils of calves infected with the LR mutant virus for 4 or 6 days (Table 1). Conversely, these same transcripts were not consistently detected in tonsils of calves acutely infected with wt BHV-1 at 4 or 6 days p.i. Mx1a RNA was detected in total RNA prepared from calves infected with the LR mutant virus or wt BHV-1, as well as uninfected bovine tonsils (data not shown), suggesting this gene is constitutively expressed in tonsils. In contrast to the re- sults obtained in tonsils, IFN RNA was not readily detected in TG of calves infected with the LR mutant virus or wt BHV-1 for 4 or 6 days. Although the main site of BHV-1 latency is TG sensory neurons (Jones, 1998, 2003), pharyngeal tonsils are an important site for viral replication and persistence or latency (Perez et al., 2005; Winkler et al., 1999, 2000).

Calves latently infected with the LR mutant virus do not reactivate from latency following DEX treatment (Inman et al., 2002). This suggested that an IFN response would not occur in calves latently infected with the LR mutant virus following DEX treatment. Since wt BHV-1 or the LR rescued virus reactivates from latency and shed virus from the nasal or ocular cavity following DEX treatment (Inman et al., 2002), a strong IFN response was expected to occur. Twenty-four hours after DEX treatment was used to examine IFN RNA expression in TG or tonsils because abundant viral gene expression occurs in 
Table 1. Expression of IFN RNA in tonsils or TG of calves acutely infected with BHV-1

RNA was extracted from tonsils or TG of calves infected with wt BHV-1 or the LR mutant virus for 4 or 6 days p.i. The animal ID\# was used to identify the respective calves. The clinical data and virus titres obtained from these calves following infection were previously described (Inman et al., 2001 and Inman et al., 2002). +, Transcript was detected; -, transcript was not detected; ND, not determined.

\begin{tabular}{|c|c|c|c|c|c|c|c|c|c|c|c|c|}
\hline \multirow[t]{3}{*}{ Virus } & \multicolumn{12}{|c|}{ Acute infection } \\
\hline & \multicolumn{8}{|c|}{ Tonsil } & \multicolumn{4}{|c|}{ Trigeminal ganglion } \\
\hline & \multicolumn{4}{|c|}{4 days p.i. } & \multicolumn{4}{|c|}{6 days p.i. } & \multicolumn{2}{|c|}{4 days p.i. } & \multicolumn{2}{|c|}{6 days p.i. } \\
\hline Calf ID\# & 47 & 52 & 25 & 31 & 38 & 51 & 20 & 16 & $\frac{\text { wt BHV-1 }}{47}$ & $\frac{\text { LR mut }}{31}$ & $\frac{\text { wt BHV-1 }}{51}$ & $\frac{\text { LR mut }}{20}$ \\
\hline IFN- $\alpha 1$ & - & - & + & - & - & - & - & + & - & - & - & - \\
\hline IFN- $\beta 2$ & - & - & + & + & - & - & + & + & - & - & - & - \\
\hline IFN- $\beta 3$ & - & - & + & - & - & - & - & + & - & - & - & - \\
\hline IFN- $y$ & - & - & + & - & - & - & + & + & - & - & - & - \\
\hline Mx1a & + & + & + & + & + & + & + & + & - & - & - & - \\
\hline
\end{tabular}

TG at this time (Inman et al., 2002; Rock et al., 1992; Winkler et al., 2000, 2002). At $24 \mathrm{~h}$ after DEX-induced reactivation, IFN- $\beta$ and IFN- $\gamma$ RNA expression were detected in tonsils prepared from wt-infected calves, but not tonsils of calves infected with the LR mutant virus (Table 2). In contrast, IFN RNA was not readily detected in TG of calves latently infected with the LR mutant virus or wt BHV-1 following DEX treatment. The IFN-inducible gene, Mx1a, was consistently detected in TG (Table 2), suggesting that low levels of IFN are expressed in TG as previously demonstrated (Winkler $e$ t al., 2002).

\section{Discussion}

Collectively, these studies suggested that higher levels of LR-RNA expression stimulated the IFN response during early stages of productive infection, in particular IFN- $\beta 3$ RNA expression. Since BHV-1 grows efficiently in cultured cells in the presence of high levels of IFN$\alpha$ (Hohle et al., 2005), this may explain why the LR mutant virus, wt BHV-1 or LR rescued virus grow to similar titres in cultured bovine cells (Inman et al., 2001). These findings may also help to explain why the LR mutant virus grows less efficiently in certain tissues (Inman et al., 2001, 2002), and calves infected with the LR mutant virus have enhanced immune infiltration in TG during acute infection (Perez et al., 2006). The mechanism by which LR-RNA induces IFN expression may be due to the formation of double-stranded RNA, a potent inducer of the IFN response. Since overexpression of LR gene products, including LR-RNA, in transient transfection assays has no obvious effect on IFN- $\beta$ promoter activity (Henderson et al., 2005), the ability of LR-RNA to base pair with bICP0 mRNA appears to be responsible for double-stranded RNA formation during productive infection. It is also possible that LR-RNA may selectively activate the bovine IFN- $\beta 3$ promoter because IFN- $\beta 3$ RNA was strongly stimulated following infection with the LR mutant virus (Figure 3a and b).

There appear to be three potential reasons for why the LR mutant virus expressed higher levels of LR-RNA during early phases of productive infection: (i) $25 \mathrm{bp}$ of wt sequences near ORF-2 were deleted, (ii) sequences containing three stop codons and an EcoRI restriction

Table 2. Expression of IFN RNA in tonsils or TG during reactivation from latency

Calves latently infected with wt or the LR mutant virus were treated with DEX to initiate reactivation from latency as described previously (Inman et al., 2002). At $24 \mathrm{~h}$ after DEX treatment, tonsils and TG were obtained. RNA was extracted from tonsils or TG of calves infected with wt BHV-1 or the LR mutant virus for 4 or 6 days p.i. RT-PCR was performed using primers described in Supplementary Table S1. Procedures for RT-PCR were described previously (Perez et al., 2006). + , Transcript was detected; -, transcript was not detected; ND, not determined.

\begin{tabular}{|c|c|c|c|c|c|}
\hline \multirow[b]{4}{*}{ Calf \# } & \multicolumn{5}{|c|}{ Reactivation from latency } \\
\hline & \multicolumn{3}{|c|}{ Tonsil } & \multicolumn{2}{|c|}{ Trigeminal ganglion } \\
\hline & \multicolumn{2}{|c|}{ wt BHV-1 } & \multirow{2}{*}{$\begin{array}{c}\text { LR } \\
\text { mutant } \\
233\end{array}$} & \multirow{2}{*}{$\begin{array}{c}\text { wt BHV-1 } \\
245\end{array}$} & \multirow{2}{*}{$\begin{array}{l}\text { LR } \\
\text { mutant } \\
233\end{array}$} \\
\hline & 228 & 245 & & & \\
\hline IFN- $\alpha 1$ & - & - & - & - & - \\
\hline IFN- $\beta 1$ & - & + & - & - & - \\
\hline IFN- $\beta 2$ & + & + & - & - & - \\
\hline IFN- $\beta 3$ & - & - & - & - & - \\
\hline IFN- $\gamma$ & + & ND & - & - & - \\
\hline Mx1a & + & + & + & + & + \\
\hline
\end{tabular}


enzyme site were inserted at the $5^{\prime}$ terminus of ORF-2 and/or (iii) the LR mutant virus does not synthesize two proteins encoded by the LR gene. LR protein expression is not detected until the late phases of productive infection (Hossain et al., 1995; Jiang et al., 1998), suggesting LR proteins do not regulate IFN RNA levels. Although LR-RNA expression was detected at 2 and $4 \mathrm{~h}$ p.i. with the LR mutant virus (Figure 1c and d), this does not necessarily mean that LR-RNA was expressed under IE conditions. A previous study demonstrated that two BHV1 early genes (ribonucleotide reductase and thymidine kinase) are expressed $2 \mathrm{~h}$ p.i. of bovine cells (Schang \& Jones, 1997), suggesting that early expression of LRRNA expression can occur as early as $2 \mathrm{~h}$ p.i. High levels of bICP0 RNA are expressed throughout productive infection because two promoters drive bICP0 RNA expression: an IE promoter and a separate early promoter (Fraefel et al., 1994). Consequently, premature expression of LR-RNA would increase the probability that hybridization occurs with bICP0 RNA during the early stages of infection.

Following infection of cattle, LR-RNA (Devireddy \& Jones, 1998), but not other viral genes (unpublished data), are detected in TG at 1 day p.i., suggesting that LR-RNA is the first abundant viral transcript expressed in sensory neurons. Consequently, LR-RNA sequences may promote the early phases of establishing latency by binding to bICP0 mRNA sequences, which would inhibit productive infection by reducing bICP0 levels and inducing an earlier IFN response. Our previous studies also indicate that expression of an LR protein promotes survival of infected neurons by inhibiting apoptosis (Ciacci-Zanella et al., 1999; Lovato et al., 2003). In conclusion, we propose that premature expression of LR-RNA by the LR mutant virus, in the absence of LR protein expression, leads to survival of a subset of infected neurons that can establish latency but are unable to reactivate from latency (Inman et al., 2002).

\section{Acknowledgments}

This work was supported by two USDA grants (200501554 and 2006-01627), and in part from two Public Health Service grants (R21AI069176 and 1P20RR15635 to the Nebraska Center for Virology).

\section{References}

Abril, C., Engels, M., Limman, A., Hilbe, M., Albini, S., Franchini, M., Suter, M. \& Ackerman, M. (2004). Both viral and host factors contribute to neurovirulence of bovine herpesvirus 1 and 5 in interferon receptor-deficient mice. J Virol 78, 3644-3653.
Bratanich, A. C., Hanson, N. D. \& Jones, C. (1992). The latencyrelated gene of bovine herpesvirus 1 inhibits the activity of immediate-early transcription unit 1. Virology 191, 988-991.

Chomczynski, P. \& Sacchi, N. (1987). Single step method of RNA isolation by acid guanidinium thiocyanate-phenolchloroform extraction. Anal Biochem 162, 156-159.

Ciacci-Zanella, J., Stone, M., Henderson, G. \& Jones, C. (1999). The latency-related gene of bovine herpesvirus 1 inhibits programmed cell death. J Virol 73, 9734-9740.

Devireddy, L. R. \& Jones, C. (1998). Alternative splicing of the latency-related transcript of bovine herpesvirus 1 yields RNAs containing unique open reading frames. J Virol 72, 7294-7301.

Devireddy, L. R. \& Jones, C. (1999). Activation of caspases and p53 by bovine herpesvirus 1 infection results in programmed cell death and efficient virus release. J Virol 73, 3778-3788.

Fraefel, C., Zeng, J., Choffat, Y., Engels, M., Schwyzer, M. \& Ackermann, M. (1994). Identification and zinc dependence of the bovine herpesvirus 1 transactivator protein BICP0. J Virol 68, 3154-3162.

Geiser, V. \& Jones, C. (2005). The latency related gene encoded by bovine herpesvirus 1 encodes a small regulatory RNA that inhibits cell growth. J Neurovirol 11, 563-570.

Geiser, V., Inman, M., Zhang, Y. \& Jones, C. (2002). The latency related (LR) gene of bovine herpes virus 1 (BHV-1) can inhibit the ability of bICP0 to activate productive infection. J Gen Virol 83, 2965-2971.

Henderson, G., Perng, G.-C., Nesburn, A., Wechsler, S. \& Jones, C. (2004). The latency related gene of bovine herpesvirus 1 can suppress caspase 3 and caspase 9 during productive infection. J Neurovirol 10, 64-70.

Henderson, G., Zhang, Y. \& Jones, C. (2005). The bovine herpesvirus 1 gene encoding infected cell protein 0 (bICP0) can inhibit interferon-dependent transcription in the absence of other viral genes. J Gen Virol 86, 2697-2702.

Hohle, C., Karger, A., Konig, P., Glesow, K. \& Keil, G. M. (2005). High-level expression of biologically active bovine alpha interferon by Bovine herpesvirus 1 interferes only marginally with recombinant virus replication in vitro. J Gen Virol 86, 2685-2695.

Hossain, A., Schang, L. M. \& Jones, C. (1995). Identification of gene products encoded by the latency-related gene of bovine herpesvirus 1. J Virol 69, 5345-5352.

Inman, M., Lovato, L., Doster, A. \& Jones, C. (2001). A mutation in the latency-related gene of bovine herpesvirus 1 leads to impaired ocular shedding in acutely infected calves. J Virol 75, 8507-8515.

Inman, M., Lovato, L., Doster, A. \& Jones, C. (2002). A mutation in the latency related gene of bovine herpesvirus 1 interferes with the latency-reactivation cycle of latency in calves. J Virol 76, 6771-6779.

Inman, M., Zhou, J., Webb, H. \& Jones, C. (2004). Identification of a novel transcript containing a small open reading frame that is expressed during latency, and is antisense to the latency related gene of bovine herpes virus 1 (BHV-1). J Virol 78, 5438-5447. 
Jiang, Y., Hossain, A., Winkler, M. T., Holt, T., Doster, A. \& Jones, C. (1998). A protein encoded by the latency-related gene of bovine herpesvirus 1 is expressed in trigeminal ganglionic neurons of latently infected cattle and interacts with cyclin-dependent kinase 2 during productive infection. $J$ Virol 72, 8133-8142.

Jiang, Y., Inman, M., Zhang, Y., Posadas, N. A. \& Jones, C. (2004). A mutation in the latency related gene of bovine herpesvirus 1 (BHV-1) inhibits protein expression of a protein from open reading frame 2 (ORF-2) and an adjacent reading frame during productive infection. J Virol 78, 3184-3189.

Jones, C. (1998). Alphaherpesvirus latency: its role in disease and survival of the virus in nature. Adv Virus Res 51, 81-133.

Jones, C. (2003). Herpes simplex virus type 1 and bovine herpesvirus 1 latency. Clin Microbiol Rev 16, 79-95.

Jones, C., Geiser, V., Henderson, G., Jiang, Y., Meyer, F., Perez, S. \& Zhang, Y. (2006). Functional analysis of bovine herpesvirus $1(\mathrm{BHV}-1)$ genes expressed during latency. Vet Microbiol 113, 199-210.

Katze, M. G., Heng, Y. \& Gale, M. (2002). Viruses and interferon: fight for supremacy. Nat Rev Immunol 2, 675-686.

Kutish, G., Mainprize, T. \& Rock, D. (1990). Characterization of the latency-related transcriptionally active region of the bovine herpesvirus 1 genome. J Virol 64, 5730-5737.

Lin, R., Noyce, R. S., Collins, S. E., Everett, R. D. \& Mossman, K. L. (2004). The herpes simplex virus ICP0 RING finger domain inhibits IRF3- and IRF7-mediated activation of interferon-stimulated genes. J Virol 78, 1675-1684.

Lovato, L., Inman, M., Henderson, G., Doster, A. \& Jones, C. (2003). Infection of cattle with a bovine herpesvirus 1 (BHV-1) strain that contains a mutation in the latency related gene leads to increased apoptosis in trigeminal ganglia during the transition from acute infection to latency. $J$ Virol 77, 4848-4857.

Megyeri, K., Au, W.-C., Rosztoczy, I., Babu, N., Raj, K., Miller, R. L., Tomai, M. A. \& Pitha, P. M. (1995). Stimulation of interferon and cytokine gene expression by imiquimod and stimulation by Sendai virus utilize similar signal transduction pathways. Mol Cell Biol 15, 2207-2218.

Meyer, F., Perez, S., Jiang, Y., Zhou, Y., Henderson, G. \& Jones, C. (2007). Identification of a novel protein encoded by the latency related (LR) gene of bovine herpesvirus 1 (BHV-1). J Neurovirol 13, 569-578.

Mossman, K. L. \& Smiley, J. R. (2002). Herpes simplex virus ICP0 and ICP34.5 counteract distinct interferon-induced barriers to virus replication. J Virol 76, 1995-1998.

Mossman, K. L., Saffran, H. A. \& Smiley, J. R. (2000). Herpes simplex virus ICP0 mutants are hypersensitive to interferon. J Virol 74, 2052-2056.

Mossman, K. L., Macgregor, P. F., Rozmus, J. J., Goryachev, A. B., Edwards, A. M. \& Smiley, J. R. (2001). Herpes simplex virus triggers and then disarms a host antiviral response. J Virol 75, 750-758.

Perez, S., Inman, M., Doster, A. \& Jones, C. (2005). Latency-related gene encoded by bovine herpesvirus 1 promotes virus growth and reactivation from latency in tonsils of in- fected calves. J Clin Microbiol 43, 393-401.

Perez, S., Lovato, L., Zhou, J., Doster, A. \& Jones, C. (2006). Comparison of inflammatory infiltrates in trigeminal ganglia of cattle infected with wild type BHV-1 versus a virus strain containing a mutation in the LR (latency-related) gene. $J$ Neurovirol 12, 392-397.

Peters, G. A., Khoo, D., Mohr, I. \& Sen, G. C. (2002). Inhibition of PACT-mediated activation of PKR by the herpes simplex simplex virus type 1 Us11 protein. J Virol 75, 11054-11064.

Rock, D. L., Beam, S. L. \& Mayfield, J. E. (1987). Mapping bovine herpesvirus type 1 latency-related RNA in trigeminal ganglia of latently infected rabbits. J Virol 61, 3827-3831.

Rock, D., Lokensgard, J., Lewis, T. \& Kutish, G. (1992). Characterization of dexamethasone-induced reactivation of latent bovine herpesvirus 1. J Virol 66, 2484-2490.

Saira, K., Zhou, Y. \& Jones, C. (2007). The infected cell protein 0 encoded by bovine herpesvirus 1 (bICP0) induces degradation of interferon response factor 3 (IRF3), and consequently inhibits beta interferon promoter activity. J Virol 81, 3077-3086.

Schang, L. M. \& Jones, C. (1997). Analysis of bovine herpesvirus 1 transcripts during a primary infection of trigeminal ganglia of cattle. J Virol 71, 6786-6795.

Schang, L. M., Hossain, A. \& Jones, C. (1996). The latency-related gene of bovine herpesvirus 1 encodes a product which inhibits cell cycle progression. J Virol 70, 3807-3814.

Tikoo, S. K., Campos, M. \& Babiuk, L. A. (1995). Bovine herpesvirus 1 (BHV-1): biology, pathogenesis, and control. Adv Virus Res 45, 191-223.

Valarcher, J.-F., Furze, J., Wyld, S., Cook, R., Conzelman, K.-K. \& Taylor, G. (2003). Role of alpha/beta interferons in the attenuation and immunogenecity of recombinant bovine respiratory syncytial viruses lacking NS proteins. J Virol 77, 8426-8439.

Wilson, V., Jeffreys, A. J. \& Barrie, P. A. (1983). A comparison of vertebrate interferon gene families detected by hybridization with human interferon DNA. J Mol Biol 166, 457-475.

Winkler, M. T., Doster, A. \& Jones, C. (1999). Bovine herpesvirus 1 can infect $\mathrm{CD}^{+} \mathrm{T}$ lymphocytes and induce programmed cell death during acute infection of cattle. $J$ Virol 73, 8657-8668.

Winkler, M. T. C., Doster, A. \& Jones, C. (2000). Persistence and reactivation of bovine herpesvirus 1 in the tonsil of latently infected calves. J Virol 74, 5337-5346.

Winkler, M. T., Doster, A., Sur, J. H. \& Jones, C. (2002). Analysis of bovine trigeminal ganglia following infection with bovine herpesvirus 1. Vet Microbiol 86, 139-155.

Zhang, Y. \& Jones, C. (2005). Identification of functional domains within the bICP0 protein encoded by BHV-1. J Gen Virol 86, 879-886.

Zhang, Y., Jiang, Y., Zhou, J. \& Jones, C. (2006). The bovine herpes virus 1 (BHV-1) immediate early protein (bICP0) interacts with the histone acetyltransferase p300, and these interactions correlate with stimulation of gC promoter activity. J Gen Virol 87, 1843-1851. 
Supplementary Table S1. Primers used to detect IFN response and viral gene expression All primers listed are $5^{\prime}-3^{\prime}$. The size of the PCR products are listed as base pairs (bp).

\begin{tabular}{|lllc|}
\hline Transcript & \multicolumn{1}{c}{ Forward } & \multicolumn{1}{c}{ Reverse } & $\begin{array}{c}\text { Product } \\
\text { size(bp) }\end{array}$ \\
\hline bIFN- $\alpha 1$ & CTGGCCAAGAGGAGAGTCC & AAAGCTGGAAGGTGTGTTGG & 178 \\
bIFN- $\beta 1$ & AGGAGCTACAGCTTGCTTCG & TGACCAATATGGCATCTTCC & 175 \\
bIFN- $\beta 2$ & AATGGACAGTTAAATACTGTAAGC & TAAATGTCTCCAGGGTGCTC & 178 \\
bIFN- $\beta 3$ & TCC TCTTCTACTTTCTGCCAAA & AAGGGCTTGCAGAGTGAATG & 158 \\
bIFN- $\gamma$ & ACTGCTCTGTGGGCTTTTGG & CCAAACAAACAAACACATCTAGC & 248 \\
Mx1a & TGAAGCTGAGAAGTCCATCC & CCTGGGATTGGAAGTAATG & 152 \\
ISG54 & AAAGAGCTTCCTCCCGTAGC & GAAGAAACGCCAAGAGATGC & 255 \\
ISP15 & CTGGTGAGGAACGACCAAGG & TTCATGAGGCCGTATTTCCTC & 179 \\
$\beta-A c t i n$ & GTGGGGCGCCCCAGGCACCA & CTCCTTAATGTCACGCACGATTTC & 550 \\
L3D & ACTGCGGCTCGAAAGTTAAG & GTGCGAGAAAGCCTCCTG & 241 \\
1980 & - & CGTCTGGCGCGGCCCGGGCT & \\
\hline
\end{tabular}

Perez, S., Meyer, F., Saira, K., Doster, A. and Jones, C. (2008). Premature expression of the latency-related RNA encoded by bovine herpesvirus type 1 correlates with higher levels of beta interferon RNA expression in productively infected cells. J Gen Virol 89, 1338-1345. 